\title{
CLARICE LISPECTOR: O LIVRO DA REVELAÇÃO DO PRAZER
}

CLARICE LISPECTOR: THE BOOK OF THE REVELATION OF PLEASURE

Thiago Cavalcante Jeronimo*

RESUMO: Este artigo analisa as três epígrafes que abrem o romance Uma aprendizagem ou o livro dos prazeres, de Clarice Lispector, como prenúncios do processo formativo que sua protagonista vivenciará. Tratam-se paratextos que se articulam na tessitura de todo o romance, direcionando-o à renovação possibilitada pela morte dos estereótipos, conceitos sociais e pessoais de Loreley, personagem principal da narrativa. Percebe-se que o trio de citações (Bíblico, Poético e Dramático) além de possibilitar ao leitor uma observação quanto ao repertório de leitura - cultural e literário - da escritora, evidencia uma perspectiva concisa o mesmo tempo, ampla de significacoos do romance clariciano. ro Nota-se ainda que as tres epigrafes comungam de um posicionamento metafórico/apocaliptico condizente à autoconsciência da protagonista, isto é, confluem à revelação, a tornar claro o que está obscuro no processo de ser e de estar no mundo de Loreley. A fundamentação teórica conflui, sobretudo, à pesquisa do crítico literário Gerard Genette concernente à obra Paratextos editoriais.

PALAVRAS-CHAVE: Clarice Lispector; Epígrafes; Paratextos; Revelação.
* thiagocavalcante@live.com

Doutorando e mestre em Letras pela Universidade Presbiteriana Mackenzie (UPM-SP). O presente trabalho foi realizado com apoio da Coordenação de Aperfeiçoamento de Pessoal de Nivel Superior Brasil (CAPES) - Código de Financiamento 001.

ABSTRACT: This article analyzes the three epigraphs that open the novel $O$ aprendizado ou o livro dos prazeres, by Clarice Lispector, as a foreshadowing of the formative process that her protagonist experiences. As paratexts that articulate in the texture of the whole novel, they lead to the renovation made possible by the death of the stereotypes, social and personal concepts of Loreley, the main character of the narrative. It is noticed that the trio of quotations (Biblical, Poetic and Dramatic), besides allowing the reader an observation about the repertoire of reading - cultural and literary - of the writer, shows a concise perspective and at the same time a broader meaning of the novective and at the same time a broader meaning of the novel by Clarice Lispector. It is also noted that the three epigraphs share a metaphorical/apocalyptic position that is coherent with the protagonist's self-consciousness, in other words, they come to the revelation, to make clear what is obscure in the process of being in Loreley's world. The theoretical foundations proposed here converges to the research of the literary critic Gérard Genette, especially in Paratexts editorials.

KEYWORDS: Clarice Lispector; Epigraphs; Paratexts; Revelation. 

o livro dos prazeres, p. 153.

\section{INTRODUÇÃO}

Escrever acerca da obra de Clarice Lispector (1920 1977), quando ícones importantes da crítica literária já se empenharam em nortear interpretações relativas a seus escritos ao longo dos mais de setenta e quatro anos da publicação de seu primeiro romance (Perto do coração selvagem foi publicado em 1943), é um desafio, válido de renovação, para qualquer pesquisador. Ocorrência que é possível precisamente porque o texto de Clarice, como a atribuição direcionada pelo crédulo aos textos sagrados, se renova a cada estação em que é lido, a cada vivência sondada na vida de seus leitores "de alma já formada".

Considerando essa experiência de renovação, busca-se neste estudo valorizar o romance Uma aprendizagem ou o livro dos prazeres concernente à produção instigante, fluida e pensante de sua autora. Para alguns críticos, o livro lançado por Clarice em 1969 é uma obra que se distancia de seus textos consagrados, Laços de família e A paixão segundo G.H., por exemplo; entretanto, o que se nota na história de Loreley e Ulisses - protagonistas deste romance -, além de uma aproximação conciliadora para com os desfechos de suas heroínas anteriores e, para além de uma história clichê de amor romântico, é a unificação intelectual, espiritual e corporal de suas personagens que são cultuadas nessa narrativa: "Nós é um".
A trajetória de Lóri no decorrer desse livro que é "o meio do ca minho"2, expressão alcunhada por Romilda Mochiuti ao interpretar a pontuação de abertura e fechamento da narrativa, perfila-se neste artigo sob a ótica interpretativa das três epígrafes que abrem o texto cla ricia no; paratextos que se articulam na tessitura de todo o romance, direcionando-o à renovação possibilitada pela morte dos estereótipos, conceitos sociais e pessoais de sua protagonista.

O sexto romance de Clarice Lispector, Uma aprendizagem ou o livro dos prazeres, dentro do conjunto escritural de sua autora, evoca em análises literá rias alacridades e contrariedades, isto é, o romance claricia no que narra o desenvolvimento da personagem Loreley desperta diversas apreciações favorecendo ou não sua concepção.

Atendo-se a essa questão no linea mento crítico que aqu se desdobrará em análise, é possível perfilhar o pensamento daqueles que leram $O$ livro dos prazeres direcionando-o à definição de literatura "malograda”, uma abordagem "apressada” para com os atributos poéticos vislumbrados na obra em questão.

Contrapelo a este posiciona mento, nomes notáveis vinculados à fortuna crítica de Lispector contemplam no texto de 1969 uma concepção de escrita inerente à poética
2. MOCHIUTI, Penelopéias silentes, p.
EM TESE
BELO HORIZONTE
v. 24
N. 2
MAIO-AG0. 2018
CAVALCANTE. Clarice Lispector: o livro da revelação do prazer
P. $11-22$ 
3. NUNES, O drama da linguagem: uma leitura de Clarice Lispector, $\mathrm{p}$. 81

4. O também cantor Caetano Veloso ao escrever acerca da cronica clariciana "Mineirinho", mencion que seu filho "Moreno, quando tinha 19 anos, leu para mim, com lágrimas nos olhos, longos trechos de Uma aprendizagem ou o livro dos prazeres. Em todos esses reencontros [com a escrita de Clarice], sempre o fluxo da vida aflorando por entre as palavras, [...] com intensidade assustadora VELOSO, 2010, p. 26). claricia na, um livro que, diante de todo o processo escritural vislumbrado por Clarice, une-se à somatória da novidade que o nome da autora representa na literatura nacional Olga de Sá, Benedito Nunes, Dirce Côrtes Riedel, Nádia Battella Gotlib são exemplos dos que enxergaram no livro Uma aprendizagem, entre as décadas de 1980 a 1990, "um romance de romances" ${ }^{3}$, isto é, O livro dos prazeres agrega traços de todos os romances até então publicados por Clarice: uma escrita constante em inovação. Ao lado desses pesquisadores, nos a nos 2000 até o presente momento, encontram-se Terezinha Goreti dos Santos, Romilda Mochiuti, Renata Tavares, Lúcia Pires, para citar alguns exemplos. Destarte, a apreciação direcionada à história lispectoriana que narra o desenvolvimento de Loreley à "personalização de sua consciência" reafirma a qualidade ficcional que é própria ao universo de Clarice Lispector.

Qualidade observada também pela cantora brasileira Zélia Duncan ${ }^{4}$ que, ao estrear uma coluna no jornal $O$ Globo, em meados de 2015, com a crônica "Sou leitora: desde criança encantada com a mágica das palavras", evidencia a surpresa e o fascínio que Uma aprendizagem ou o livro dos prazeres lhe proporcionou:

Escrever é uma farsa. Todos sabem e assumem seus papéis, como tem que ser. Desconfiei disso ao desabar para dentro de um livro de Clarice Lispector e me deparar com uma vírgula, antes de qualquer palavra. Como assim? A história começou, antes que eu abrisse o livro? Ninguém me esperou? Depois entendi que era uma quebra fundamental na minha inocência de leitora. Tudo já estava acontecendo, antes de se revelar. Claro, claríssimo, Clarice? Mas houve ainda o golpe fatal. $\mathrm{Na}$ última página do mesmo livro, depois da última palavra, lá estavam eles, dois-pontos! Mas o começo me ensinou a aceitar o fim. Eis a minha participação. O deleite daquela leitura enquanto ela durou, contida entre pontuações, que indicavam continuidade e nunca conclusão, me levou por caminhos que aceito e procuro. Caminhos sem fim. ${ }^{5}$

A pontuação, não apenas em Uma aprendizagem ou o livro dos prazeres, mas em todo o percurso narrativo de Clarice Lispector, numa poética de "respiração da frase", aponta para uma quebra nos conceitos normativos da sintaxe e da sinalética, e dá ao leitor uma narrativa com significados que se ampliam antes e depois da materialidade do texto.

Atendo-se às significações marcadas e sugeridas no texto em questão, a análise deste artigo perseguirá as possíveis interpretações das epígrafes materializadas na tessitura de Uma aprendizagem ou o livro dos prazeres. Paratextos que prenunciam o processo de autoconscientização de Loreley, protagonista deste livro.
5. DUNCAN, Sou leitora: desde criança encantada com a mágica das palavras, $\mathrm{s} / \mathrm{p}$. 
6. Genette, Paratextos editoriais, p. 9, 10 , grifo do autor.

7. A epígrafe tem a função de acompanhar o texto para projetar nele formas de leitura, mas a epígrafe pode também funciona como comentário do texto, inscrevendo-se numa tradição de paratextos enigmáticos nos quais a significação só se esclarece ou se confirma pela leitura do texto.

\section{AS EPÍGRAFES DE UMA APRENDIZAGEM OU O LIVRO}

\section{DOS PRAZERES}

Na obra Paratextos editoriais, o crítico literário Gérard Genette empenha-se na expla nação do paratexto. Segundo o teórico francês, desde a invenção do livro moderno, as obras literárias nunca se apresentam como um texto neutro, nu, sem o reforço e o acompanhamento de certo número de produções: vem cercado de um apara to que o completa e protege, impondo-lhe um modo de usar e uma interpretação congruentes com o propósito do escritor.

Dessa forma, a apresentação editorial, nome do autor, títulos, dedicatórias, epígrafes, prefácios, notas, dentre outros, para além de regularem a leitura de um livro, complementa m o sentido do texto literário, prolongando-o satisfatoriamente. Segundo o crítico francês, paratexto

é aquilo por meio de que um texto se torna livro e se propõe como tal a seus leitores [...] Mais do que um limite ou uma fronteira estanque, trata-se aqui de um limiar, [... de um "vestíbulo", que oferece a cada um a possibilidade de entrar ou de retroceder. ${ }^{6}$

Dentre as possibilidades a nalíticas dos paratextos existentes na obra Uma aprendizagem ou o livro dos prazeres, a atenção neste estudo confluirá para as três epígrafes ${ }^{7}$ escolhidas por Clarice Lispector para acompanhar o processo de desenvolvimento de suas personagens: trio de citações que possibilitam ao leitor ${ }^{8}$, além de uma observação quanto ao repertório de leitura - cultural e literário - da escritora, uma abordagem concisa e, ao mesmo tempo, a mpla de significações do texto principal, isto é, O livro dos prazeres.

A definição, grosso modo, de Genette para o paratexto epígrafe vai de encontro às interpretações comuns do vocábulo: "uma citação colocada em enxergo, em destaque, geralmente no início de obra ou de parte de obra: 'em destaque' significa literalmente fora da obra, o que é uma coisa exagerada." $\mathrm{O}$ vocábulo em destaque, fora, é o termo ressignificado por Genette. Para o crítico, a epígrafe, isto é, "o enxergo é mais uma borda da obra, geralmente mais perto do texto". ${ }^{10}$

Dessa forma, a análise das epígrafes do sexto romance de Clarice Lispector, consideradas neste estudo como borda do romance, são paratextos "em estado de dicionário", ${ }^{11}$ ou seja, delega m interpretações ao leitor ${ }^{12}$ para uma compreensão ainda mais rica da produção articulada da escritora brasileira.
8. Estando coligada ao texto principal "epigrafar é sempre um gesto mudo cuja interpretação fica Paratextos editoriais, p. 141.

\section{GENETTE, Paratextos editoriais, $\mathrm{p}$. 131 , grifo do autor.}

10. GENETTE, Paratextos editoriais, $\mathrm{p}$ 131 , grifo do autor.

11. ANDRADE, A rosa do povo, p. 12.

2. “Chega mais perto e contempla as palavras. / Cada uma / tem mil a forma neutra".
EM TESE

BELO HORIZONTE

v. 24

N. 2

MAIO-AGO. 2018

CAVALCANTE. Clarice Lispector: o livro da revelação do prazer

P. $11-22$ 


\section{APOCALIPSE OU O LIVRO DA REVELAÇÃO}

Três são as epígrafes escolhidas por Clarice Lispector para, possivelmente, nortear a compreensão de Uma aprendizagem ou o livro dos prazeres. A primeira é uma referência explícita ao texto cristão oriundo do livro escrito pelo apóstolo João, intitulado Apocalipse, isto é, O livro da revelação.

Depois disto olhei, e eis que vi uma porta aberta no céu e a primeira voz que ouvi era como a trombeta que falava comigo, dizendo: sobe aqui, e mostrar-te-ei as coisas que devem acontecer depois destas. APOCALIPSE, IV, 1.

A explanação recorrente ao nome Apocalipse, encontrada na Bíblia Sagrada King James, assevera que:

A expressão grega apokalipsis "revelação", significa literalmente "tirar o manto", isto é, "descobrir", "tornar claro algo obscuro", “à luz da compreensão”. Aqui a mensagem (revelação) vem de Cristo, por meio de um "anjo intermediário”, e é ministrada a João a través de símbolos, que é o sentido do termo grego semaiño "significar", "expressar" (ensinar por simbologia). Essa compreensão nos leva à chave da interpretação geral deste livro: Ensinamento simbólico. ${ }^{13}$

Ao nome Apocalipse, além de revelação, é possível atrelar o sentido de profecia, discurso assustador, nebuloso, obscuro, uma vez que, com sua simbologia, ${ }^{14}$ seus desdobramentos acerca dos últimos dias se tornam incontáveis.

A finalidade recorrente ao livro cristão é alertar os crédulos acerca das dificuldades que a comunidade cristã enfrentaria naquele tempo, bem como incentivá-los a guardar sua fé em Cristo Jesus, resistindo às provações terrenas e mantendo firme a esperança de que o retorno ${ }^{15}$ messiânico, a segunda vinda de Cristo, não tardaria. ${ }^{16}$ É válido clarear que, a volta de Jesus, pautada no livro de João, engloba a profecia de, após o cumprimento das perseguições e catástrofes apocalípticas, "[...] novo céu e nova terra"17, isto é, uma renovação a toda existência.

O mito de Ulisses e Penélope, na Odisseia, tem em seu fluxo e contexto o retorno do herói a Ítaca, isto é, ao reencontro com sua esposa. Penélope, esperançosa para rever Ulisses, tece e destece a mortalha de seu sogro, resistindo aos apelos de seus pretendentes. As palavras postas em negrito evidenciam uma correlação de sentidos às três narrativas - homérica, bíblica e clariciana -, a resistência (provação) desencadeada no retorno (recompensa).

Focalizando as escrituras reveladas ao apóstolo João, é válido destacar dois versos que são emblemáticos no texto sagrado: "Quem tem ouvidos ouça o que o Espírito diz às
14. Como na época de João, as dominantes começavam a impor o chamado "culto de adoração ao imperador", o apóstolo sent ao imperador", o apóstolo sente os cristãos a se manterem fiéis os cristăos a se manterem fiéis motivos, incluindo o cultural (o estilo literário peculiar), o místico (a obra é fruto de uma experiência de êxtase espiritual) e o da segurança (era fundamental que a mensagem chegasse às igrejas sem a censura ou o bloqueio do exército romano). Por estas razões, o discurso está aqui delineado sob símbolos, metáforas e ilustrações diversas.

15. “A palavra 'apocalipse' tornou-se um termo técnico para a igreja primiva e passou a designar a Cristo, o Messias, no final dos tempos. Portanto, o'apocalipse' a 'revelação' da pessoa do Senhor Jesus Cristo como Redentor do Jesus Cristo como Redentor do absoluto do Mal em todas as suas formas e expressões". Bíblia Sagrada, p. 2463.

16. É válido marcar que os cristãos primitivos aguardavam a volta de Cristo naquela epoca, fato reiterado por João à igreja em Filadélfia: “Eis que venho sem demora; guarda o que tens, para que ninguém tome tua coroa". Apocalipse, 3:11.

17. Apocalipse, 21:1. 
18. Apocalipse, 2:11.

19. Apocalipse, $21: 7$.

20. Apocalipse, 2, 17, grifo nosso

21. Lispector, $A$ descoberta do mundo, p. 378.

22. Lispector, Uma aprendizagem ou 0 livro dos prazeres, p. 13 igrejas"18 e "Quem vencer herdará todas as coisas"19. Um verso do Apocalipse que contém as duas expressões, como impulso encorajador aos cristãos que sofreriam perseguições, é distendido na profecia retransmitida por João da seguinte forma: "Quem tem ouvidos, ouça o que o Espírito diz às igrejas: Ao que vencer da rei eu de comer do maná escondido, e dar-lhe-ei uma pedra branca, e na pedra um novo nome escrito, o qual ninguém conhece senão aquele que o recebe" ${ }^{20}$. O livro da revelação, em síntese, pressupõe em seu discurso uma ordem à Igreja Primitiva: ouvir.

Ulisses é aquele que terá que ouvir tanto o canto de sedução instaurado por Lóri, como o seu silêncio. Ulisses ouve e possibilita, como mentor, um suporte necessário à aprendizagem de Loreley, e esta ta mbém terá que se ouvir Ouvir sua condição humana. "Deus ouve, mas eu me ouvirei?”, ${ }^{21}$ mas compete a Ulisses, inicialmente, a dimensão profética atrelada ao novo nome que, após sua aprendizagem, a protagonista Lóri herdará. Com efeito, no parágrafo de abertura de Uma aprendizagem, a busca de uma nova identidade é posta em evidência: "Ele [Ulisses] dissera uma vez que queria que ela, ao lhe perguntarem seu nome, não respondesse 'Lóri' mas que pudesse responder 'meu nome é eu', pois teu nome, dissera ele, é um eu”. ${ }^{22}$
É no terceiro parágrafo do romance que a busca de um novo nome, em um sentido profético, é claramente aludida ao divino: "Deitada na palma transparente da mão de Deus, não Lóri mas o seu nome secreto que ela por enqua nto não podia usufruir"23. Aqui, o "por enquanto" pode ser considerado o meio do caminho da aprendizagem, que é a forma como o romance clariciano é estruturado, e é somente após o desfecho simbólico do romance que, se relacionado ao sentido de "novo céu e nova terra", a expressão apocalíptica tem seu significado: "as coisas que devem acontecer depois destas”. Por consequente, no processo narrativo de Uma aprendizagem, da vírgula aos dois-pontos, Ulisses terá que silenciar sua voz professoral e ouvir. Loreley silenciará seu canto e voz, despojando-se de "roupas" e "maquiagens" para iniciar um novo ciclo de vida.

Ouvir pressupõe um impulso para que a protagonista consiga se reconhecer não mais no nome contido no seu registro de nascimento, Loreley, mas ao que está dentro do seu nome, ao "eu" que requer passagem. Olga de Sá, ao a nalisar Uma aprendizagem ou o livro dos prazeres, marca, justamente, a audição apontada a Ulisses como passaporte para uma nova possibilidade de vida:

[...] deixando suas máscaras de pintura, ela [Lóri] acede à via do conhecimento amoroso, corpo a corpo com a vida. Ulisses,
23. Lispector, Uma aprendizagem ou o livro dos prazeres, p. 14
EM TESE

BELO HORIZONTE

v. 24

N. 2

MAIO-AGO. 2018

CAVALCANTE. Clarice Lispector: o livro da revelação do prazer

P. $11-22$ 
o professor, cala a sua voz didática e se rende ao silêncio das palavras, para esperar o amadurecimento das estações. São elas que marcam o tempo vivo da aprendizagem. ${ }^{24}$

É com teor profético que Uma aprendizagem ou o livro dos prazeres tem seu desfecho. Os dois-pontos, considerados uma sequência na narrativa, compostos de significados delegados a um leitor a tua nte, evidenciam, ta mbém, "as coisas que devem acontecer depois destas", isto é, possivelmente, "novo céu e nova terra", uma novidade de vida condicionada à audição.

\section{AUGUSTO DOS ANJOS OU O POETA DAS SOMBRAS}

A segunda epígrafe marca uma estrofe do poema "Monólogo de uma sombra", do poeta paraiba no Augusto dos Anjos. ${ }^{25}$ Clarice reformula o poema em Uma aprendizagem ou o livro dos prazeres, isto é, transcreve o texto de forma a eliminar versos inteiros da estrofe escolhida, bem como palavras dos versos acolhidos. Evidentemente, essa reformulação acarreta um novo significado poético que vai de encontro ao postulado pelo poeta. Se no poeta a morte é finitude, em Clarice a morte se reveste de uma possível novidade de vida. No texto clariciano, a estrofe que, em seu registro oficial tem seis versos, aparece com apenas três:

Provo

Que a mais alta expressão da dor

Consiste essencialmente na alegria

Já o texto fonte, que abre o único livro de Augusto dos Anjos, Eu, tem sua estrofe com o seguinte registro:

Provo desta maneira ao mundo odiento

Pelas grandes razões do sentimento,

Sem os métodos da abstrusa ciência fria

E os trovões gritadores da dialética,

Que a mais alta expressão da dor estética

Consiste essencialmente na alegria. ${ }^{26}$

Um dos temas recorrentes ao poeta paraibano Augusto dos Anjos é a degradação, a precariedade humana. Em seus poemas, a linguagem é trabalhada dando vazão a um pessimismo extremo desencadeado em uma musicalidade poética, atributos que corroboraram para uma nova expressividade na poesia brasileira.

Alfredo Bosi pontua que Augusto dos Anjos “[...] entre Cruz e Sousa e os modernistas", é "o mais original dos poetas brasileiros", ${ }^{27}$ Para o crítico, essa posição "deve-se ao caráter original, paradoxal, a té mesmo chocante, da sua linguagem, tecida de vocábulos esdrúxulos e a nimada
26. Anjos, Toda poesia, p. 90.

27. BOSI, História concisa da literatura brasileira, p. 287. 
28. BOSI, História concisa da literatura brasileira, p. 288

29. “Em sua teoria, Schopenhauer atribui o sofrimento humano à incessante vontade de vida, ao desejo que, uma vez satisfeito, apenas resultará em novos desejos. a falta do objeto de desejo a caus das dores humanas. Definida a vontade como força metafisica e irresistivel, a controlar os impulsos sexuais e as outras manifestaçôes de vida e de morte, no mundo orgânico e inorgânico, o homem aparece como simples joguete manipulado por forças perversas, capazes de submetê-lo aos seus caprichos. É esse o grande dram da existência". Macedo, $E$ u rio da ruína, p. 60

30. BOSI, História concisa da literatura brasileira, p. 289

31. "[... Schopenhauer] não crê na regeneração de uma indole corrompida. Em contrapartida, Clarice descobre que a linguagem dos desejos que animam o psiquismo humano empreende mudanças no querer, despertando no ser um desejo de criar nova vida." LIMA, O percurso das personagens de Clarice Lispector,
p. 230.

32. LIMA, $O$ percurso das personagens de Clarice Lispector, p. 229-230.

33. LIMA, O percurso das personagens de Clarice Lispector, p. 169 de virulência pessimista sem igual em nossas letras". ${ }^{28}$ Pessimismo, de acordo com o pesquisador, semelhante ao do filósofo alemão Arthur Schopenhauer ${ }^{29}$, "[...] que identifica na vontade-de-viver a raiz de todas as dores" ${ }^{30}$

A ficção de Clarice Lispector ora adere, ora se contrapõe ao pensamento de Schopenhauer. ${ }^{31}$ A pesquisadora Bernadete Grob-Lima, ao estabelecer vínculos entre o pensamento do filósofo alemão com os textos claricianos, esclarece:

[... A ficção clariciana] concorda com a premissa do filósofo de que não existimos para sermos felizes, o máximo "bem-estar que podemos alcançar na vida é o de contemplar as experiências superadas com o poder de nossas próprias forças. [...] Para Clarice, superar as adversidades da vida com o poder de suas forças é um privilégio daqueles que sabem aplicá-las adequadamente. Isso implica o domínio da linguagem como meio de persuasão das potências transformadoras do homem. ${ }^{32}$

Efetivamente, as personagens de Clarice Lispector "[... vivencia m o bem-estar no âmbito da luta; o verdadeiro prazer está em sentir o poder de suas forças, empregando todos os meios para encontrar a situação apropriada ao exercício delas" ${ }^{33}$ Clarice atribui à protagonista de Uma aprendizagem a necessidade de, por meio de suas angústias, enfrentar a dor para a concretude de uma nova possibilidade de vida. O contraste ao poema de Augusto dos Anjos e ao pensamento filosófico de Schopenhauer se dá porque em Clarice o enfrentamento da dor ocasiona um novo pulsar de vida. Sob essa premissa, a recusa da dor, em Lóri, ocasiona a impossibilidade da aprendizagem. "Pensou: eu nunca tive a minha dor. Por falta de grandeza, sofrerá suportavelmente tudo o que nela havia a sofrer. Mas agora sozinha. [...] Angústia também era o medo de sentir enfim a dor." ${ }^{34}$ Lóri é a personagem de Clarice que "[...] reunia toda a sua força para parar a dor. Que dor era? A de existir? A de pertencer a alguma coisa desconhecida? A de ter nascido?". ${ }^{35}$ Indagações narrativas que culminam num excerto que ponto-chave para compreender a hesitação da personagem "A vida inteira tomara cuidado em não ser grande dentro de si para não ter dor"36.

É possível estabelecer um contraponto entre as epígrafes até aqui analisadas. Se na primeira o tema apocalipse, revelação, é pano de fundo, na segunda, a escuridão tem seu espaço perceptível. Em "Monólogo de uma sombra", a escuridão (sombra) é acolhida de forma a marcar a degradação física humana, abrindo o livro do poeta paraibano para uma abordagem que tem como tema uma nova expressão estética condicionada à dor, à morte, ao universo das sombras.
34. Lispector, Uma aprendizagem ou o livro dos prazeres, p. 66-67.

35. Lispector, Uma aprendizagem ou livro dos prazeres, p. 49

36. Lispector, Uma aprendizagem ou livro dos prazeres, p. 56 
"Monólogo de uma sombra", como já referido em seu título, tem como voz poética as ponderações pessimistas de uma sombra acerca da degradação humana, a decomposição da matéria. O início do poema é grafado com aspas pontuação que terá seu desfecho somente na vigésima-oitava estrofe, o que confere ao discurso do eu-lírico, propriamente dito, apenas as três estrofes finais do poema. Cabe evidenciar que Clarice Lispector recria significados ao marcar em sua epígrafe, reformulado, o texto de Augusto dos Anjos: "A mais alta expressão da dor estética" torna-se "A mais alta expressão da dor". A retirada do sema "estética" possibilita uma amplitude de significados correlacionados ao sofrimento. Sendo assim, a dor em Clarice não é restrita aos atributos artísticos, mas tem seus desdobramentos no ser humano.

Augusto dos Anjos, como considerado neste ensaio, postula um pessimismo chocante em seus poemas, entretanto, "Monólogo de uma sombra", cabe frisar, abre passagem para uma expressão otimista sujeita à dor estética, isto é, à arte. Clarice, em sentido contrário de uma sombria articulação pessimista, que tem como negativa a desarticulação humana para com a vida, isto é, ao fluxo contínuo de satisfações versus insatisfações, pontua na voz de Ulisses o significado atrelado à reformulação do poema de Augusto dos Anjos:
Na desarticulação haverá um choque entre você e a realidade, é preferível estar preparada para isso, Lóri, a verdade é que estou contando a você parte do meu caminho já percorrido. Nos piores momentos, lembre-se: quem é capaz de sofrer intensamente, também pode ser capaz de intensa alegria. ${ }^{37}$

A desarticulação, processo comum às personagens de Clarice Lispector, possibilita a experiência epifânica, a passagem de um estado ao outro. À vista disto, ao final do livro, após a entrega mútua corporal dos protagonistas, o sofrimento expresso na narrativa não é o da dor, mas as personagens sofrem dessa vez "de vida e de amor". ${ }^{38} \mathrm{Um}$ novo processo é instaurado.

\section{PAUL CLAUDEL OU A ALEGRIA É MAIS FORTE}

A terceira epígrafe é marcada em itálico na língua francesa e tem em seu registro a informação de que sua autoria é atribuída ao Oratório de Paul Claudel para a música de Honneger, Jeanne d'Arc au bucher. ${ }^{39}$ Segue inscrição:

Jeanne: Je ne veux pas mourir! J'ai peur!

...

Il y a la joie qui est la plus forte!

Pela tradução ${ }^{40}$ da epígrafe, pode-se correlacionar o texto de Claudel à reformulação do poema de Augusto dos Anjos
37. Lispector, Uma aprendizagem ou o livro dos prazeres, p. 98-99.

38. Lispector, Uma aprendizagem ou o livro dos prazeres, p. 159.

39. Joana d'Arc entre as chamas.

40. A tradução da obra de Claudel no Brasil é atribuída a Dom Marcos Barbosa. O tradutor, em seu prefácio à edição brasileira, afirma
que Joana d'Arc "não é apenas um episódio francês; ela pertence também à história da Igreja e do mundo." Barbosa apud Claudel, Joana d'Arc em chamas, p. 9. Ao sintetizar a biografia de Joana d'Arc, Barbosa define sua vivência como "[...] a epopeia da pastorinha que arranca aos invasores inglese várias cidades da França, leva o Delfim a Rheims para ser sagrado, e morre, afinal, nas mãos dos ingleses e seus aliados, queimada como feiticeira" Barbosa apud Claudel, Joana d'Arc em chamas, p. 9-10. 
41. Sublinhe-se que a primeira heroína de Clarice Lispector, apresentada em Perto do coração selvagem, nomeada Joana. Olga de Sá cria um vinculo comparativo entre a Joana de Clarice e a Santa Joana. Após analisar a carga semântica das palavras que designam os quatros elementos no romance inaugural clariciano (terra, fogo, ar e água), a crítica compara a heroín de Clarice Lispector a Joana d'Arc, ambas ligadas à audição: “Joana d'Arc ouvia vozes, que não entendia e guiaram seu destino. Joana d'Arc, por que não? Uma pona déc da ficção, atormentada de palaras, de vozes, que foram de palavias, de vozes, que fora". Sá, $A$ escritura de Clarice Lispector p. 231.

2. Cabe a citação da leitura de Affonso Romano de Sant'Ann acerca do processo criativo de Clarice Lispector: "Clarice, aquela que se deixou incendiar na fogueir da linguagem Clarice, p. 26 marcada por Clarice, isto é, por meio do sofrimento, enfrentando-o, nasce a possibilidade de um novo ciclo de vida.

Joana: Eu não quero morrer! Eu tenho medo!

Há a alegria que é a mais forte!

É possível sintetizar a complexa, simbólica e mitológica figura histórica de Joana d'Arc da seguinte maneira Joana ${ }^{41}$ ainda criança, ouvia vozes que a direcionam à missão de libertar a França dos invasores ingleses; embora fosse mulher, liderou um exército, coroou o seu rei e teve um destino trágico: foi queimada viva como herege. ${ }^{42}$

Ao registrar em seu texto como epígrafe três versos do Oratório dramático de Paul Claudel, que principia a história de Joana d'Arc pelo fim, isto é, da morte para a vida Clarice acolhe frases soltas do drama para formar sua citação. Embora os três versos esteja m acoplados à última cena do drama, isto é, à décima primeira cena, Clarice em sua epígrafe reformula-os, como fez com o poema augustino. Abaixo, é possível constatar que a fala do Povo foi subtraída por Clarice na abertura de Uma aprendizagem ou o livro dos prazeres.
"Joana: - Eu não quero morrer!

O povo, numa só voz: - Ela diz que ela não quer morrer.

Joana: - Eu tenho medo!" 43

O terceiro verso, "Há a alegria que é a mais forte" 44 , transcrito por Clarice na reformulação de sua epígrafe, possui desdobramentos no Oratório dramático. A princípio não é de Joana a afirma tiva de que existe uma alegria mais forte que a morte. É de uma "Voz ${ }^{45 "}$ ", primeiramente, a marcação no texto dramático de que a alegria que é mais forte. Sua afirmativa é completa da seguinte forma: "Voz: - Há a alegria que é mais forte! Há o a mor que é mais forte! Há Deus que é mais forte." ${ }^{\prime 6}$

Metaforizando o rompimento de correntes por Joana, logo após a fala dessa Voz, inicia-se o posicionamento de liberdade da heroína, liberdade condicionada à morte. Após o rompimento com suas a marras, a protagonista de Claudel une sua afirmativa à fala da Voz: "Joana: - Eu vou! Eu vou! Eu estou indo! Eu quebrei as correntes! Eu parti! Há a alegria que é mais forte!" ${ }^{47}$. Joana quebra as correntes, que, conforme a voz narrativa, “[...] prendiam Joana a Joana. [...] as correntes que prendiam a alma ao corpo" ${ }^{48}$ Após a morte física de Joana, Claudel deixa evocar, já no final de seu Oratório, a voz da própria Joana: “- Há o a mor que é mais forte! Há Deus que é mais forte.” ${ }^{49}$ Alegria, amor e Deus,
43. Claudel, Joana d'Arc entre chamas, p. 112.

44. Claudel, Joana d'Arc entre chamas, p. 117.

45. São seis as personagens do drama Joana d'Arc entre as chamas: Joana, São Domingos, A Virgem, Porcus, Santa Catarina e Santa Margarida. Justapostas às vozes destas personagens, há vozes que se fundem ao drama: $\mathrm{O}$ coro, $\mathrm{A}$ voz, Vozes de criança, Vozes, O Povo, Vozes no céu, etc.

46. Claudel, Joana d'Arc entre chamas, p. 117.

47. Claudel, Joana d'Arc entre chamas, p. 117.

48. Claudel, Joana d'Arc entre chamas, p. 117.

49. Claudel, Joana d'Arc entre chamas, p. 117. 
50. São João, 11:25

51. Lispector, $A$ hora da estrela, p. 79. de acordo com o teatro de Paul Claudel, são os elementos consoladores que tornam o sofrimento suportável.

Ao compasso dos preceitos cristãos, já sinalizados na a nálise da primeira epígrafe, a vida eterna é condicionada à morte. Sendo assim, a decomposição física não é condição de término existencial para a doutrina cristã. Fato alicerçado por meio das palavras de Cristo em que a morte é vencida pela ressureição: "Quem crê em mim, ainda que esteja morto, viverá." ${ }^{0}$ Joa na d'Arc, cristã, por ter essa premissa atrelada à sua fé, mesmo debaixo de tortura psicológica e física, manteve sua convicção de ressureição, esperança vincada ao cristianismo. Sob esse aspecto, é possível frisar a possibilidade de um novo patamar de vida após o ciclo de sofrimento, de intensa dor e morte. Não seria esse um possível percurso ta mbém incrustado no texto $A$ hora da estrela, em que a autora mortifica a personagem Macabéa, "grávida de futuro" ${ }^{51}$, numa ascensão epifânica (pós-atropela mento) de um novo estado de vida?

Postulada como herege, Joana d'Arc teve seu nome retratado após quinhentos anos de sua morte pelo poder máximo da Igreja Católica, o Papa Bento XV, que a reconheceu como mártir da fé, canonizando-a como santa dessa instituição religiosa. A protagonista de Uma aprendizagem ou o livro dos prazeres, ao contrário de uma canonização mística
- uma vez que a corrente narrativa em Clarice se manifesta por meio da condição humana -, vivencia por meio de uma "mortalha narrativa", isto é, o constante limiar de suas experimentações, a possibilidade de criar um novo desejo de vida.

Assim analisadas, as três epígrafes que abrem o romance Uma aprendizagem ou o livro dos prazeres, além de desvelar o repertório de leitura de Clarice Lispector, preludiam o processo formativo que a Loreley é destinado: a morte dos estereótipos, dos conceitos sociais e pessoais à concretude de sua autoconsciência.

\section{REFERÊNCIAS}

ANDRADE, Carlos Drummond de. A rosa do povo. São Paulo: Companhia das Letras, 2012

ANJOS, Augusto dos. Toda poesia. 5. ed. Rio de Janeiro: José Olympio, 2016.

BíBLIA SAGRADA. Tradução King James Atualizada. Edição de Estudo - 400 anos. São Paulo: Abba Press Editorada e Divulgadora e Sociedade Bíblica Ibero-Americana, 2012.

BOSI, Alfredo. História concisa da literatura brasileira. 43. ed. São Paulo: Cultrix, 2006

CLAUDEL, Paul Joana d'Arc entre as chamas. Trad. Dom

Marcos Barbosa. Rio de Janeiro: Agir, 1963. 
DUNCAN, Zélia. Sou leitora: desde criança encantada com a mágica das palavras. $\mathbf{O}$ Globo, Rio de Janeiro, $1^{\circ}$ maio 2015. Disponível em: <http://oglobo.globo.com/cultura/souleitora-16027172>. Acesso em: 08 nov. 2017.

GENETTE, Gérard. Paratextos editoriais. Trad. Álvaro Faleiros. Cotia, SP: Ateliê Editorial, 2009.

LIMA, Bernadete Grob. O percurso das personagens de Clarice Lispector. Rio de Janeiro: Garamond, 2009.

LISPECTOR, Clarice. A hora da estrela. Rio de Janeiro: Rocco, 1998

Uma aprendizagem ou o livro dos prazeres. Rio de Janeiro: Rocco, 1998

A descoberta do mundo. Rio de Janeiro: Rocco, 1999

MACEDO, Anne Greice Soares Ribeiro. Eu, operário da ruína: as intersecções entre arte, doença e morte em Augusto dos

Anjos. 2006. 167 f. Dissertação (Mestrado em Letras) - Programa

de Pós-graduação em Letras e Linguística, Instituto de Letras,

Universidade Federal da Bahia, Salvador, 2006

MOCHIUTI, Romilda. Penelopéias silentes. 2006. 166 f. Tese (Doutorado em Letras) - Programa de Pós-Graduação em Língua Espanhola e Literaturas Espanhola e Hispano-americana, do

Departamento de Letras Modernas da Faculdade de Filosofia

Letras e Ciências Humanas da Universidade de São Paulo, São Paulo, 2006
NUNES, Benedito. $\mathbf{O}$ drama da linguagem: uma leitura de Clarice Lispector. São Paulo: Ática, 1995.

SÁ, Olga de. A escritura de Clarice Lispector. 2. ed. Rio de Janeiro: Vozes, 1993.

SANT'ANNA, Affonso Romano de. O ritual epifânico do texto. In: SANT'ANNA, Affonso Romano de; COLASANTI, Marina. Com Clarice. São Paulo: Editora Unesp, 2013.

VELOSO, Caetano. Apresentação da crônica "Mineirinho". In: LISPECTOR, Clarice. (Org. de Teresa Montero) Clarice na cabeceira: crônicas. Rio de Janeiro: Rocco, 2010.

Recebido em: 02-11-2018 Aceito em: 26-11-2018 